Supporting Information For:

\title{
A portable, robust, stable and tunable calibration source for gas-phase nitrous acid (HONO)
}

\author{
M. Lao ${ }^{1}$, L. R. Crilley ${ }^{1}$, L. Salehpoor ${ }^{1}$, T. C. Furlani ${ }^{1}$, I. Bourgeois ${ }^{2,3}$, J. A. Neuman ${ }^{2,3}$, A. W. \\ Rollins $^{2}$, P. R. Veres ${ }^{2}$, R. A. Washenfelder ${ }^{2}$, C. C. Womack ${ }^{2,3}$, C. J. Young ${ }^{1}$, and T. C. \\ VandenBoer ${ }^{1, *}$ \\ ${ }^{1}$ Department of Chemistry, York University, Toronto, $O N$ \\ ${ }^{2}$ NOAA Chemical Sciences Laboratory, Boulder, CO \\ ${ }^{3}$ Cooperative Institute for Research in Environmental Sciences, University of Colorado, \\ Boulder, $\mathrm{CO}$
}

\section{*Communicating Author: tvandenb@yorku.ca}

\section{S1. Rationale for components selected for custom-built permeation oven}

The custom-built permeation oven (Figs. S1-4) is comprised of a bent aluminium bent plate (exact dimensions provided in Fig. S2), temperature controller, solid state relay, custom-built four-channel aluminium heating block, cartridge heater with integrated thermocouple, and PFA tubing connected with Swagelok ${ }^{\circledR}$ fittings. The PFA tubing was interfaced with four 2-way stainless steel valves (SS-43GS6-LL, Swagelok $^{\circledR}$ ) to provide gas flow independently to each channel of the oven.

Gas flow to the system is provided by a source of dry compressed air, either from a cylinder or a zero-air generator at $20 \mathrm{psi}(138 \mathrm{kPa})$. The flow can be turned on and off to each of the four permeation channels in the aluminum heating block $\left(20.3 \times 7.7 \times 7.7 \mathrm{~cm}(8 \times 3 \times 3\right.$ ") $) 1$ x w x h, Fig S2) using 2-way Swagelok ${ }^{\circledR}$ valves (Weston Valve \& Fitting Ltd., Mississauga, ON). The flow through each channel is regulated by a 50micron critical orifice (Lenox Laser, Glen Arm, MD; SS-4-VCR-2-50) to $58 \mathrm{sccm}$. The aluminum heating block (Al-block) houses four $1 / 2$ " PFA tubes to provide inert oven surfaces. Each are mounted within machined holes passing through the center of the short axis of the block. Permeation devices (PDs) can be placed inside the $1 / 2$ " PFA ovens to emit stable quantities of their chemical contents (Section S.2). From the input of the oven to all downstream applications, Swagelok ${ }^{\circledR}$ or Entegris PFA fittings were used to minimize sorption effects for generated gases.

The thermal system is composed of three critical components: a temperature controller, temperature sensor and a heat source. All components were purchase from either Omega ${ }^{\mathrm{TM}}$ Environmental (St. Eustache, QC) or Allied Electronics, Inc. (Fort Worth, TX). The temperature controller regulates the temperature of the system by receiving an input signal (measurement) from the thermocouple to compare to its setpoint value. An output signal will be generated if the input value is below the temperature-control setpoint. The output signal is sent to a solid-state relay which enables the heater function and increases the temperature. A proportional-integral-differential (PID) temperature controller (Omega ${ }^{\mathrm{TM}} ; \mathrm{CN} 7823$ ) monitors and sets the temperature of the Al block shown in Fig. S4. Using PID mode regulates the temperature of the system automatically by using feedback from the thermocouple and associated heating element to compensate for any changes relative to the set point. The PID controller is programmed to match the appropriate thermocouple (Type $\mathrm{K}$ used here). The PID parameters are adjusted by using the auto tune function to give the precise control $\left( \pm 0.1^{\circ} \mathrm{C}\right)$ without overshooting the set point. The solid-state relay (Allied; SSR, D1210, Crydom) switches the heating cycle by converting the $5 \mathrm{~V} \mathrm{DC}$ output from the temperature controller to $120 \mathrm{~V}$ AC used to operate the heating element. To dissipate the energy required for switching, the SSR was 
mounted on an aluminium heat sink (Allied; HS172, Crydom) and protected by a Bussman rectifier fuse (Omega $^{\text {TM}}$; Tron, KAX-10 A) against excess current flow that could result from a latching failure. The fuse holder (Omega ${ }^{\mathrm{TM}}$; FB-1) allows easy replacement of a blown fuse in the circuit. A cartridge heater with an integrated $\mathrm{K}$-type thermocouple housed in a high-temperature incoloy sheath (Omega ${ }^{\mathrm{TM}}$; CIR, $300 \mathrm{~W}, 120$ V) is inserted into a $20.3 \mathrm{~cm}(8$ ") hole with a 3/8" internal diameter, on the long axis of the Al-block. The heater is a high watt density cartridge with maximum working temperature of $760{ }^{\circ} \mathrm{C}$ and F-type leads with fiberglass insulation. The thermocouple measures temperature by the thermoelectric effect which results in a voltage. A K-type thermocouple consists of chromel (Ni-Cr) and alumel (Ni-Al) alloys that generates an accurate voltage in the temperature range of 0 to $1250^{\circ} \mathrm{C}$.
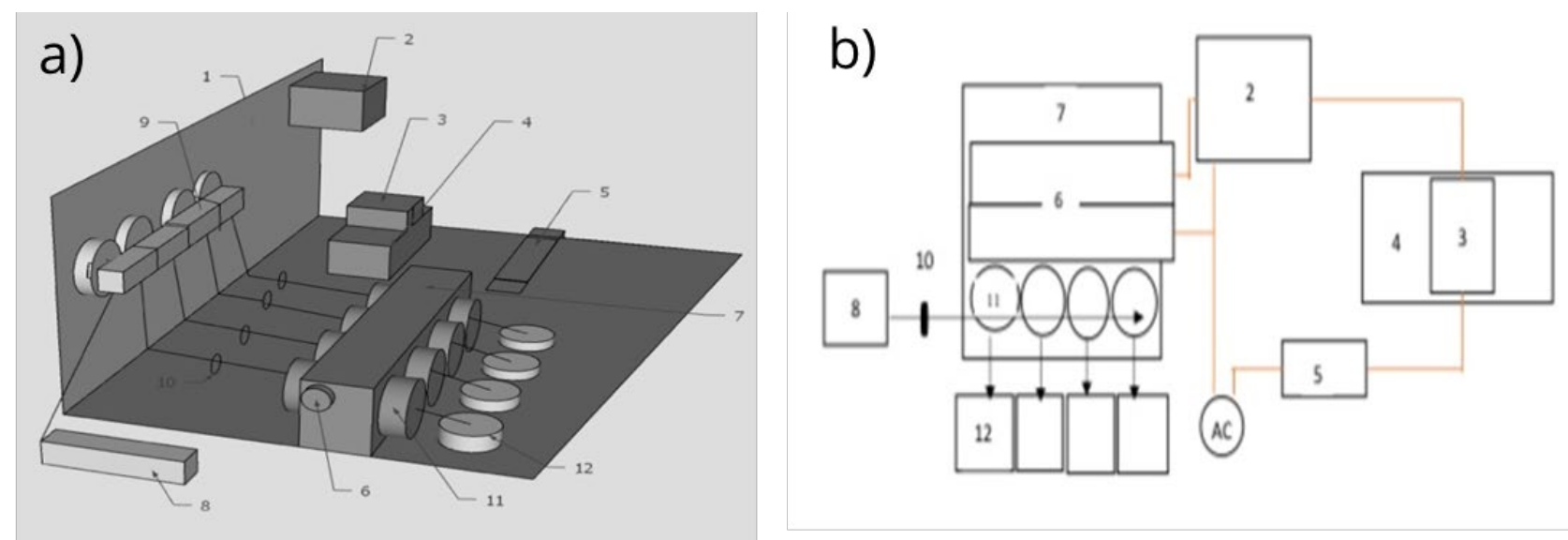

Figure S1. Three (a) and two (b) dimension layout schematics of permeation-oven components on the bent aluminium plate (1), with mounted temperature controller (2), solid state relay (3) and its heat sink (4), electrical fuse (5), cartridge heater with integrated thermocouple (6), aluminum block (7), source of dry compressed air (8), 2-way gas valve (9), critical orifice (10), PFA oven (11), and gaseous output to external system. Black lines represent PFA lines guiding gas flows throughout the system.

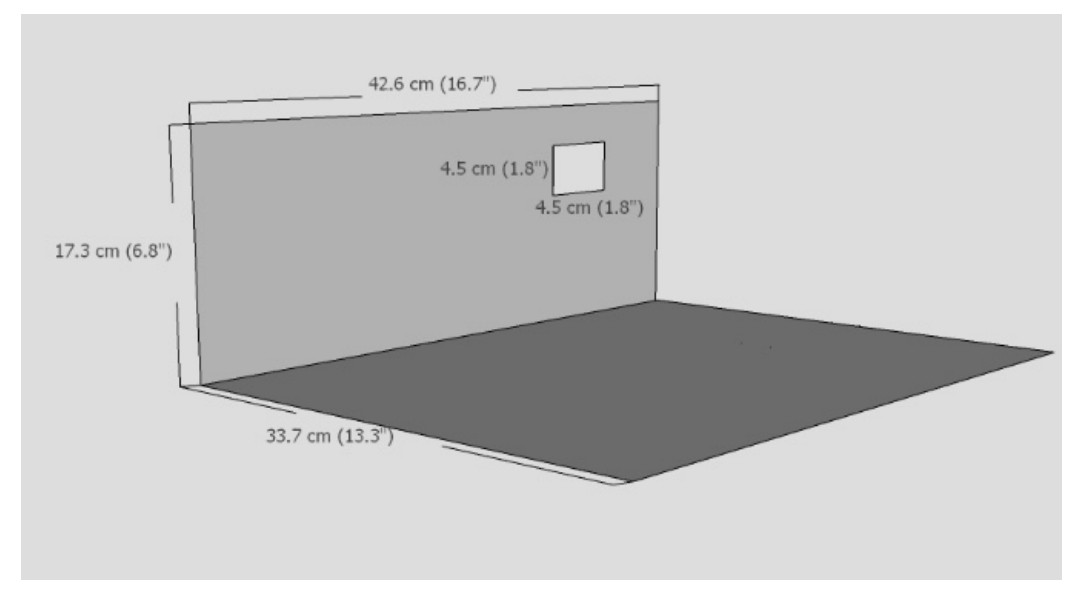

Figure S2. Dimensions of bent aluminium plate and cut-out measurements to mount the temperature controller. Further holes for valves or a holder for the water impinger were created with an electric drill on an as-needed basis. 


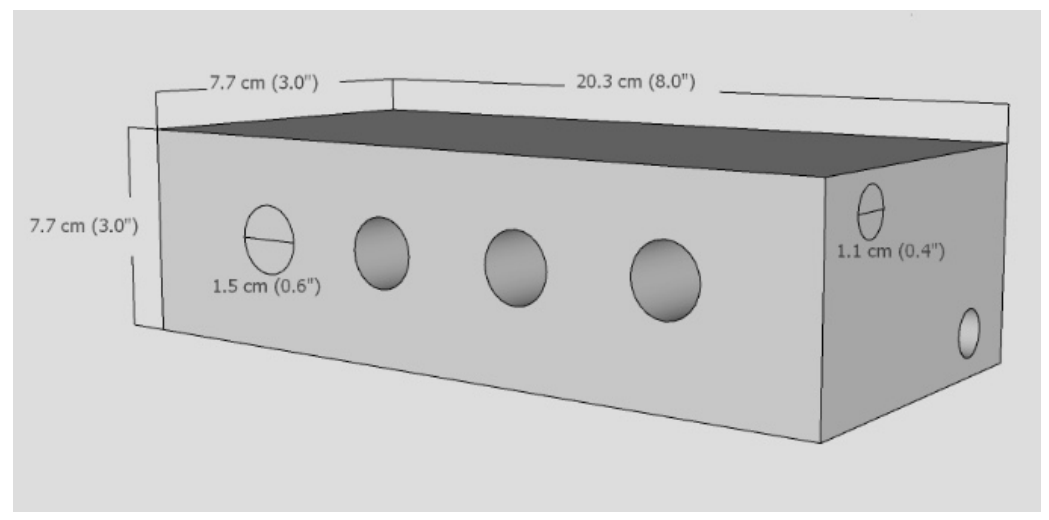

Figure S3. Dimensions and machining specifications of aluminum block oven.

\section{S1.2. Electrical connections for temperature control feedback}

Power is supplied to the entire setup from $120 \mathrm{~V}$ AC outlet capable of providing up to $15 \mathrm{~A}$ of current (Fig. S4). The temperature controller monitors the voltage signal from the thermocouple (here: yellow/+ and red/-; terminals 4 and 5, respectively; Fig. S4). When the thermocouple signal falls below the control setpoint it sends a $5 \mathrm{~V}$ signal (terminals $1(-)$ and $2(+))$ to the solid-state relay (3-32 V DC input $\mathrm{D}(-)$ and $\mathrm{C}(+))$. The solid-state relay closes the switch to deliver current to the cartridge heater leads from the AC terminals (120 V AC output $\mathrm{A}(+)$ and $\mathrm{B}(-)$; Fig. S4). The relay and cartridge heater are protected by a fuse. The entire case is grounded, with a ground wire of the power supply fixed to the bent aluminium plate.

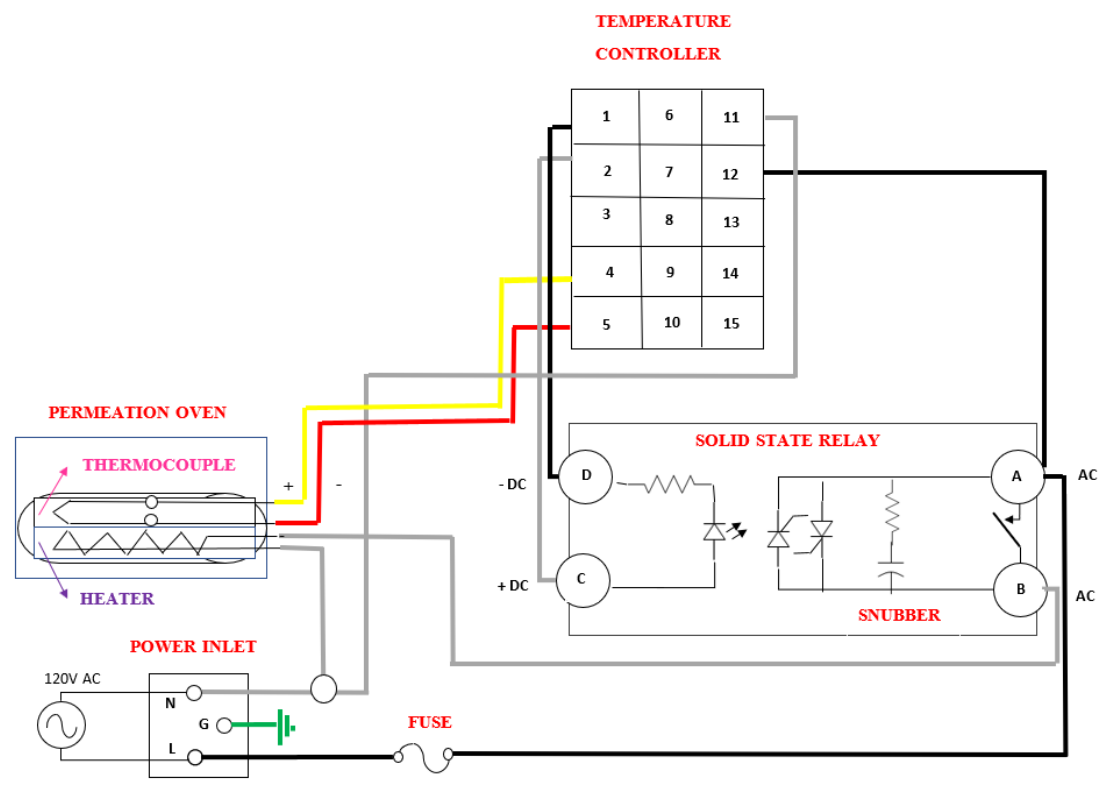

Figure S4. Schematic of the wiring and connections of the custom-built permeation oven. The power supply is distributed from the power inlet into the system through different wires consisting of live wires (black), neutral wires (grey) and a ground wire (green). The temperature controller receives signals by inputs 4 and 5 (yellow and red) connected to the thermocouple. To control the function of the heater, the temperature controller sends a signal from output 1 and 2 to input $C$ and $D$ of the solid-state relay to reach the temperature setpoint. 


\section{S2. Rationale and construction of custom permeation devices (PDs)}

The purpose of a permeation oven is to obtain a consistent quantity of gaseous analyte via a constant permeation rate, which results in a known mass per unit time delivered to an experimental system or an analytical instrument for calibration purposes. A permeation oven is typically coated or made with inert material to limit surface interactions experienced by the generated gas. The calibration gas permeates by diffusion through the porous polymer according to Fick's second law of diffusion (E1, $\left.\mathrm{m}^{2} \mathrm{~s}^{-1}\right)$. If the analyte is in an aqueous solution it is emitted into the oven as a vapor based on its effective Henry's Law constant, which is the product of its acid dissociation constant and volatility (E2, Pa mol m${ }^{-3}$; R4) (Mitchell, 2000; Scaringelli et al., 1970). The product of these two properties combine into the overall permeability term (P, Pa mol m $\mathrm{m}^{-1} \mathrm{~s}^{-1}$; E3).

$D=D_{0} e^{-\frac{\Delta E_{D}}{R T}}$

$S=S_{0} e^{-\frac{\Delta H_{S}}{R T}}$

$P=D \cdot S$

$\mathrm{NO}_{2(\mathrm{aq})}^{-}+\mathrm{H}_{(\mathrm{aq})}^{+} \rightleftharpoons \mathrm{HONO}_{(\mathrm{aq})} \rightleftharpoons \mathrm{HONO}_{(\mathrm{g})}$

Where, $\mathrm{S}_{0}$, and $\mathrm{D}_{0}$ are pre-exponential constants of solubility and diffusion. In Equations 1 and 2: $\mathrm{E}_{\mathrm{D}}$ is the activation energy for diffusion $\left(\mathrm{J} \mathrm{mol}^{-1}\right)$ and $\mathrm{H}_{\mathrm{S}}$ is the enthalpy of solvation $\left(\mathrm{J} \mathrm{mol}^{-1}\right)$, while $\mathrm{T}$ is temperature $(\mathrm{K})$ and $\mathrm{R}$ is the ideal gas constant $\left(\mathrm{J} \mathrm{mol}^{-1} \mathrm{~K}^{-1}\right)$. The permeation rate depends on temperature because both diffusion and vapour pressure are exponentially temperature dependent. Therefore, permeation ovens can provide a stable and pure emission rate that can be tuned by adjusting the temperature of the oven.

Clean air moves through the $1 / 2$ " PFA oven tubes, where the vapour emissions from PDs are accumulated, to carry them into the reaction devices, a scrubbing solution, or other instrumentation. High precision of a permeation rate can be obtained by regulating and maintaining constant temperature within $\pm 0.1^{\circ} \mathrm{C}$ because an increase of $1{ }^{\circ} \mathrm{C}$ of operating temperature results in a $10 \%$ change in sample permeation rate (Lucero, 1971). Adequate precision of our custom-built permeation oven was achieved by choosing the temperature controller, heater, and thermocouple with very strict tolerances. Long-term stability of the system can be ascertained from ion chromatography or real-time measurements (see main manuscript). Also, calibrating the permeation rate of a custom-PD can easily indicate the precision and stability of this custom-built permeation oven.

To construct a custom-PD, a length $1 / 4$ " PFA tube is filled with analyte solution and the ends are plugged. One end of the tubing is initially made malleable with a heat-gun. Once the tube is sufficiently pliable, a rod of porous PTFE ( 0.125 " diameter, P/N: 84935K64; McMaster-Carr) is carefully inserted with a twisting motion and cut to keep the tubing and rod flush. To ensure an effective seal the two materials are heated further, then compressed and rolled on a flat surface. The open-end of the PD is then filled with analyte solution until it is approximately $1 / 2$ " from the top. The PTFE plugging process is repeated to close the tube. Extra caution during this step should be taken to avoid having the solution boil over or undergoing spontaneous ignition during heating. It is worth noting that the length and quality of the seal around the porous PTFE rod can change the emission rate, where a longer plug may yield a more reliable emission rate. Generally, plugs one centimeter in length were used in this work. If the plug length is too short leakages may arise, resulting in rapid and unstable emission of the contained solution. An alternative that avoids PTFE plugs and associated leaks is to weld the tubing ends. This can be accomplished by heating the end of the tubing with a heat-gun until it is malleable, followed by pinching it with a pair of pliers to create the weld. 


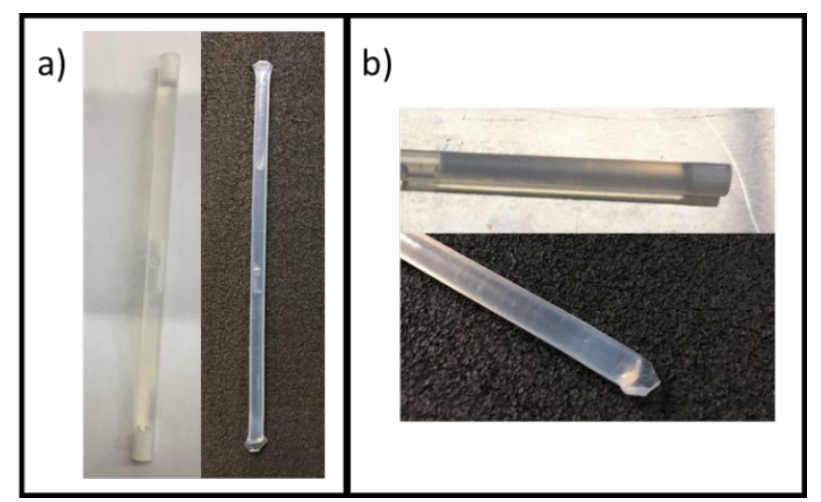

Figure S5. a) Two PDs containing analyte solution fully sealed using the porous PTFE rod (left) and PFA weld (right) techniques. b) Close-up perspective of finished PD ends after sealing by the methods of PTFE rod (top) and PFA weld (bottom).

\section{S3. Additional Supporting Figures and Tables}

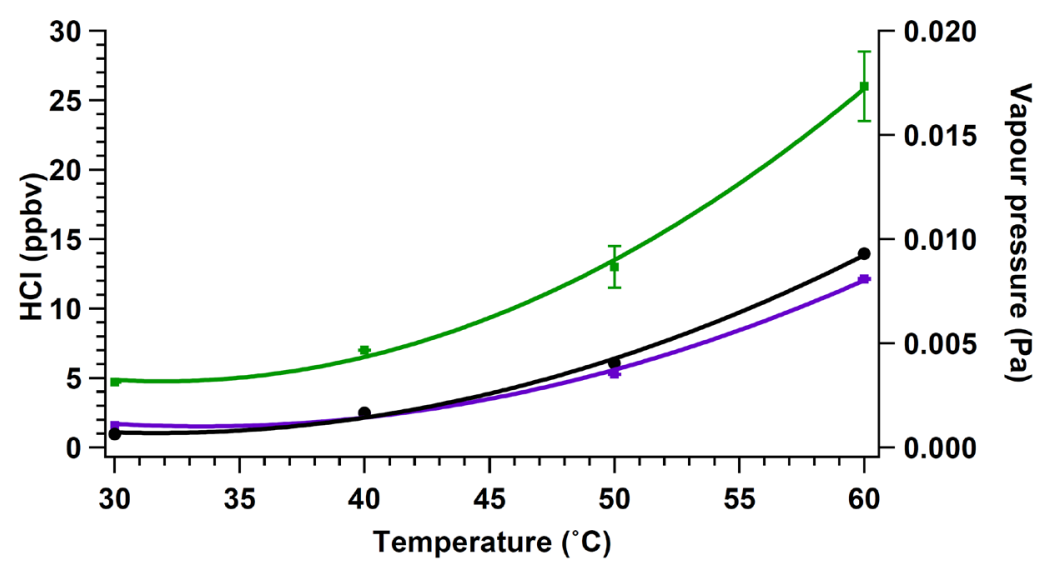

Figure S6. Mixing ratio output of two $6 \mathrm{M} \mathrm{HCl} \mathrm{PDs} \mathrm{as} \mathrm{a} \mathrm{function} \mathrm{of} \mathrm{temperature} \mathrm{(PD-6b,} \mathrm{blue;} \mathrm{PD-6c,}$ green). Calculated vapour pressure of $6 \mathrm{M} \mathrm{HCl}$ (black) solution using Henry's Law (Sander, 2015). Mean $\mathrm{HCl}$ mixing ratios measured for 30 minutes after stable signal was observed by CRDS (1-minute average, see Fig. S7). Error bars denote $1 \sigma$ standard deviation from the mean.

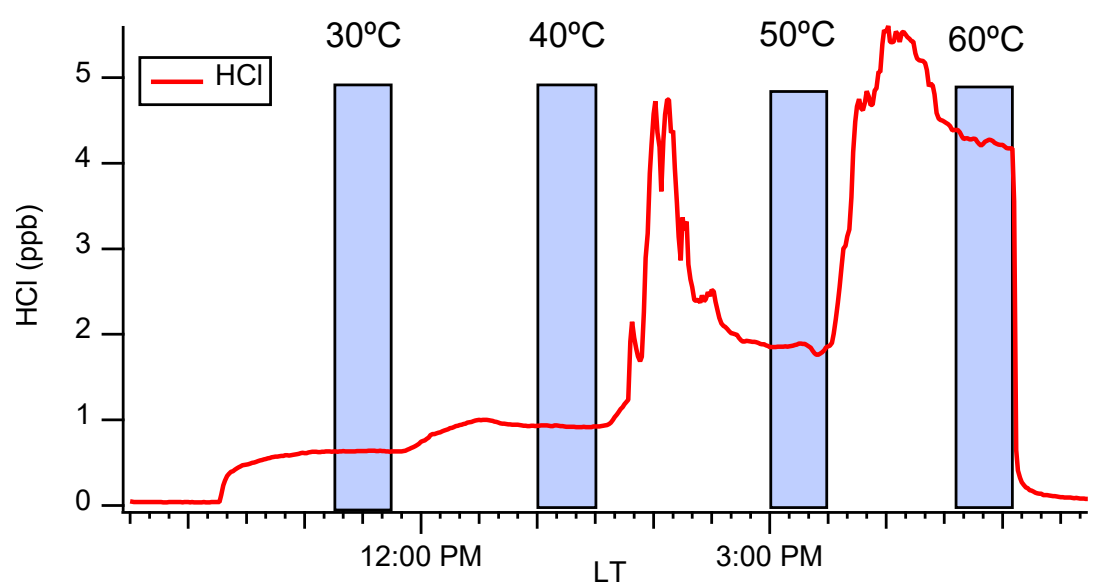

Figure S7. Time series of the measured $\mathrm{HCl}$ output from PD-6b using CRDS. The blue-shaded bars indicate the region where $\mathrm{HCl}$ output was considered stable and this data was used to calculate the variance shown in Figure S6. 
Table S1. The calculated average HONO (ppbv) output (AVG), standard deviation (SD), and standard error (SE) following the field transport simulations using $\mathrm{HCl} \mathrm{PD}-6 \mathrm{a}$ and the same $\mathrm{NaNO}_{2}$ coated device throughout all experiments. The AVG, RSD, and RSE were all calculated from data points collected after two hours of stabilization in each trial run. All experiments were background corrected by linear interpolation using zero air and five experiments had insertions of $\mathrm{Na}_{2} \mathrm{CO}_{3}$ denuder for further identification of $\mathrm{NO}_{\mathrm{x}}$ impurities $\left(^{*}\right)$. The $\mathrm{NO}_{\mathrm{x}}$ analyzer collected one-minute measurements using a $30 \mathrm{~s}$ Kalman filter.

\begin{tabular}{|c|c|c|c|c|c|c|c|}
\hline ID & $\begin{array}{l}\text { Description of Field } \\
\text { Transport Simulation }\end{array}$ & $\begin{array}{l}\text { AVG } \\
(\mathrm{ppbv})\end{array}$ & $\begin{array}{c}\mathrm{SD} \\
(\mathrm{ppbv})\end{array}$ & $\begin{array}{l}\text { SE } \\
(\mathrm{ppbv})\end{array}$ & $\begin{array}{l}\text { Data } \\
\text { Points }\end{array}$ & $\begin{array}{l}\mathrm{RSD} \\
(\%)\end{array}$ & $\begin{array}{l}\mathrm{RSE} \\
(\%)\end{array}$ \\
\hline FS1* & $\begin{array}{l}\text { Minor shaking for } 10 \mathrm{~min} \\
\text { with the oven off and PD } \\
\text { removed overnight }\end{array}$ & 2.51 & 0.548 & 0.0537 & 112 & 26.6 & 2.13 \\
\hline FS2* & $\begin{array}{l}\text { Transport by cart over rough } \\
\text { surfaces for } 10 \mathrm{~min} \text { with the } \\
\text { oven off and PD removed } \\
\text { overnight }\end{array}$ & 1.81 & 0.469 & 0.0342 & 188 & 25.9 & 1.89 \\
\hline FS3* & $\begin{array}{l}\text { Transport by cart over rough } \\
\text { surfaces for } 10 \mathrm{~min} \text { with the } \\
\text { oven off and PD removed } \\
\text { overnight }\end{array}$ & 1.68 & 0.469 & 0.0308 & 231 & 27.8 & 1.83 \\
\hline FS4* & $\begin{array}{l}\text { Minor shaking of stationary } \\
\text { setup for } 10 \mathrm{~min} \text { with the } \\
\text { oven off and PD removed } \\
\text { overnight }\end{array}$ & 2.43 & 0.447 & 0.0257 & 301 & 18.4 & 1.06 \\
\hline FS5* & $\begin{array}{l}\text { Minor shaking of stationary } \\
\text { setup for } 10 \mathrm{~min} \text { with the } \\
\text { oven off and PD removed } \\
\text { overnight }\end{array}$ & 2.13 & 0.429 & 0.0270 & 253 & 20.1 & 1.27 \\
\hline FS6 & $\begin{array}{l}\text { Oven turned off overnight } \\
\text { and Pd kept inside permeation } \\
\text { oven }\end{array}$ & 2.04 & 0.417 & 0.0240 & 300 & 20.5 & 1.18 \\
\hline FS7 & $\begin{array}{l}\text { Oven turned off and PD } \\
\text { removed overnight }\end{array}$ & 1.73 & 0.467 & 0.0340 & 189 & 27.0 & 1.97 \\
\hline FS8 & $\begin{array}{l}\text { Oven turned off and PD } \\
\text { removed overnight }\end{array}$ & 2.21 & 0.604 & 0.0454 & 177 & 27.3 & 2.05 \\
\hline
\end{tabular}




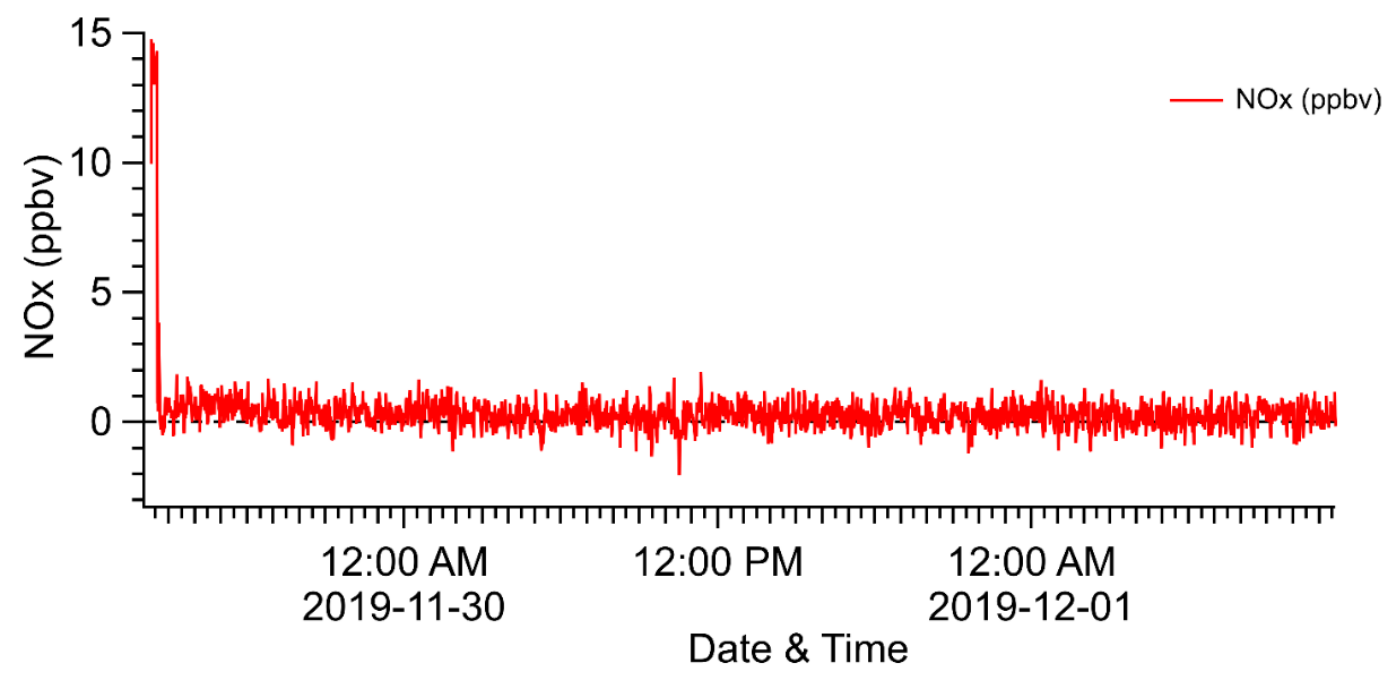

Figure S8. An example of the suitability of nitrogen gas sampled by the $\mathrm{NO}_{\mathrm{x}}$ analyzer used for background measurement and subsequent correction of observations.

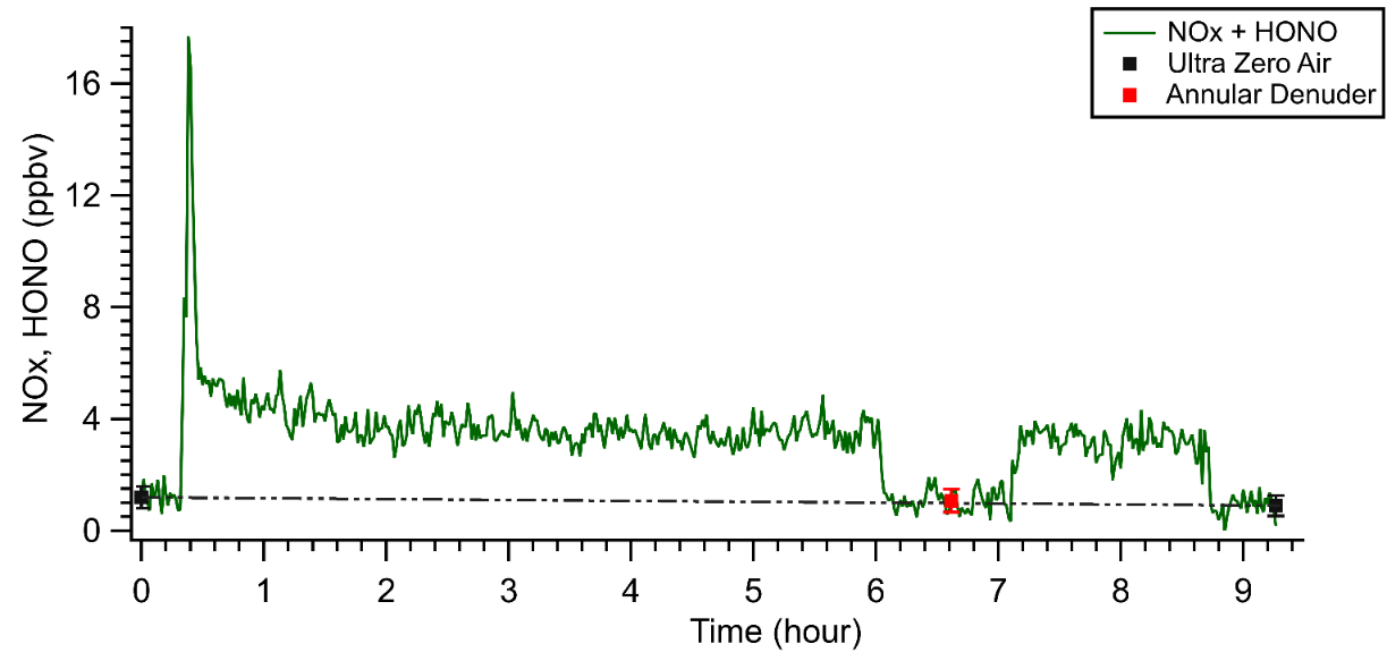

Figure S9. Run FS4 of Table S1 to demonstrate that measured signal from zero air (black square) and HONO passing through the $\mathrm{Na}_{2} \mathrm{CO}_{3}$ annular denuder (red square) are identical and therefore free of detectable $\mathrm{NO}_{\mathrm{x}}$. These negative controls were combined to create a linearly interpolated background correction over the course of experiments FS1-5 to quantify HONO. 


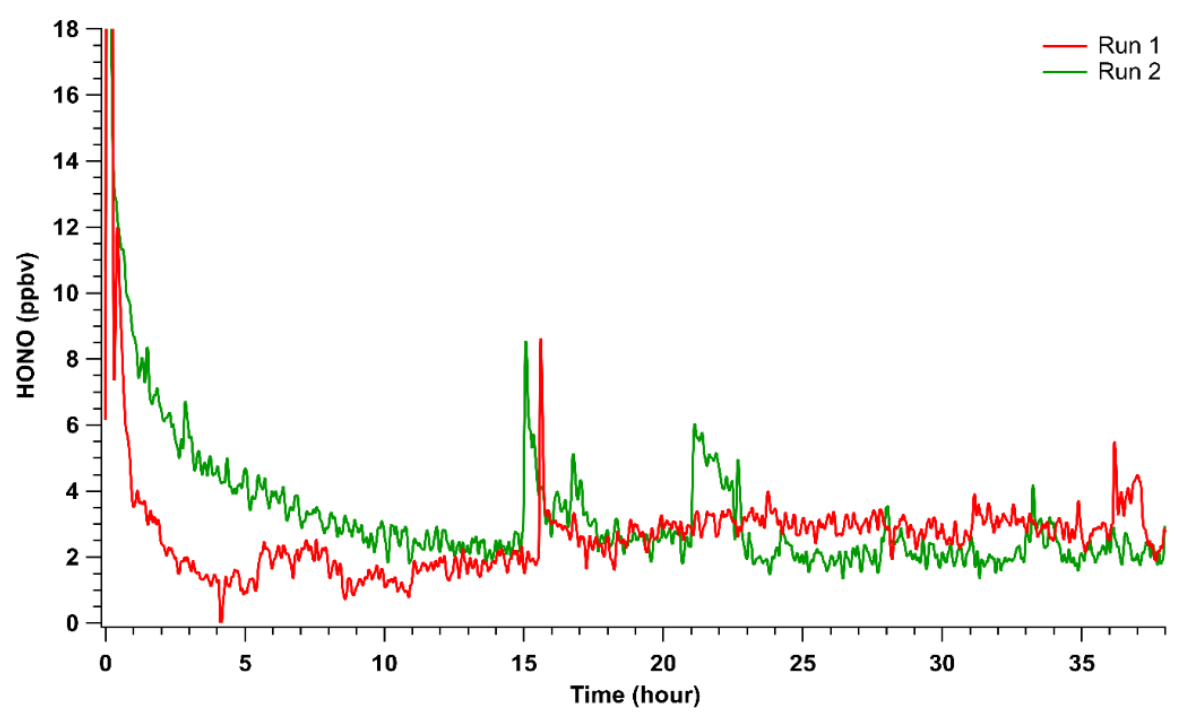

Figure S10. Reproducibility in generating $\mathrm{HONO}$ using $\mathrm{PD}-6 \mathrm{~b}$ and the same $\mathrm{NaNO}_{2}$ coated device. The red line represents the first trial of using PD-6b followed by a second trial (green) 15 days later. In the intervening time other experiments were performed which involved shutting down and restarting the system with these components. The lag in the second trial results from keeping the PD in the oven while shut down between experiments, resulting in additional $\mathrm{HCl}$ that must be reacted in the calibration system before stability is reached. The $\mathrm{NO}_{\mathrm{x}}$ analyzer mad oneminute measurements using a Kalman filter of $300 \mathrm{~s}$.

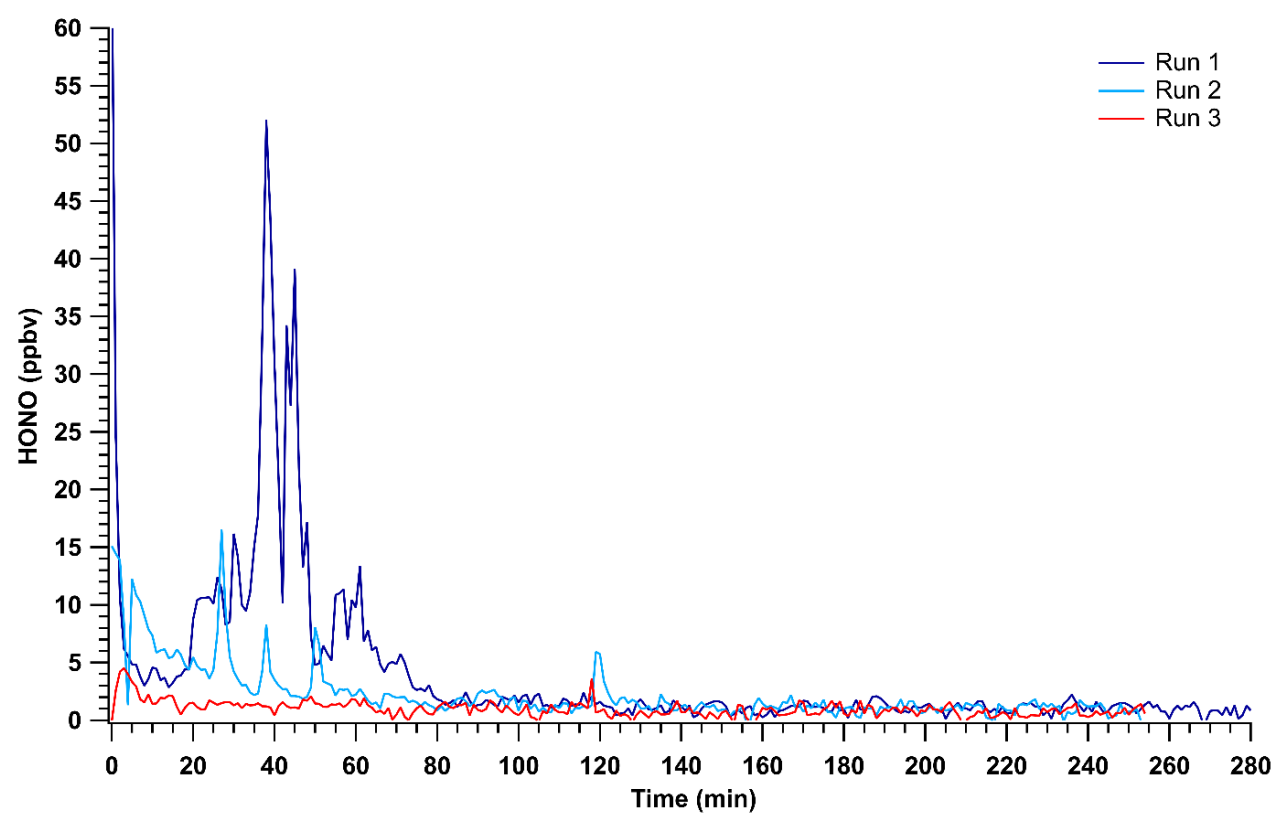

Figure S11. Determining reproducibility in generating HONO (ppbv) against time (min) using PD-1a with a used $\mathrm{NaNO}_{2}$ PFA device. 


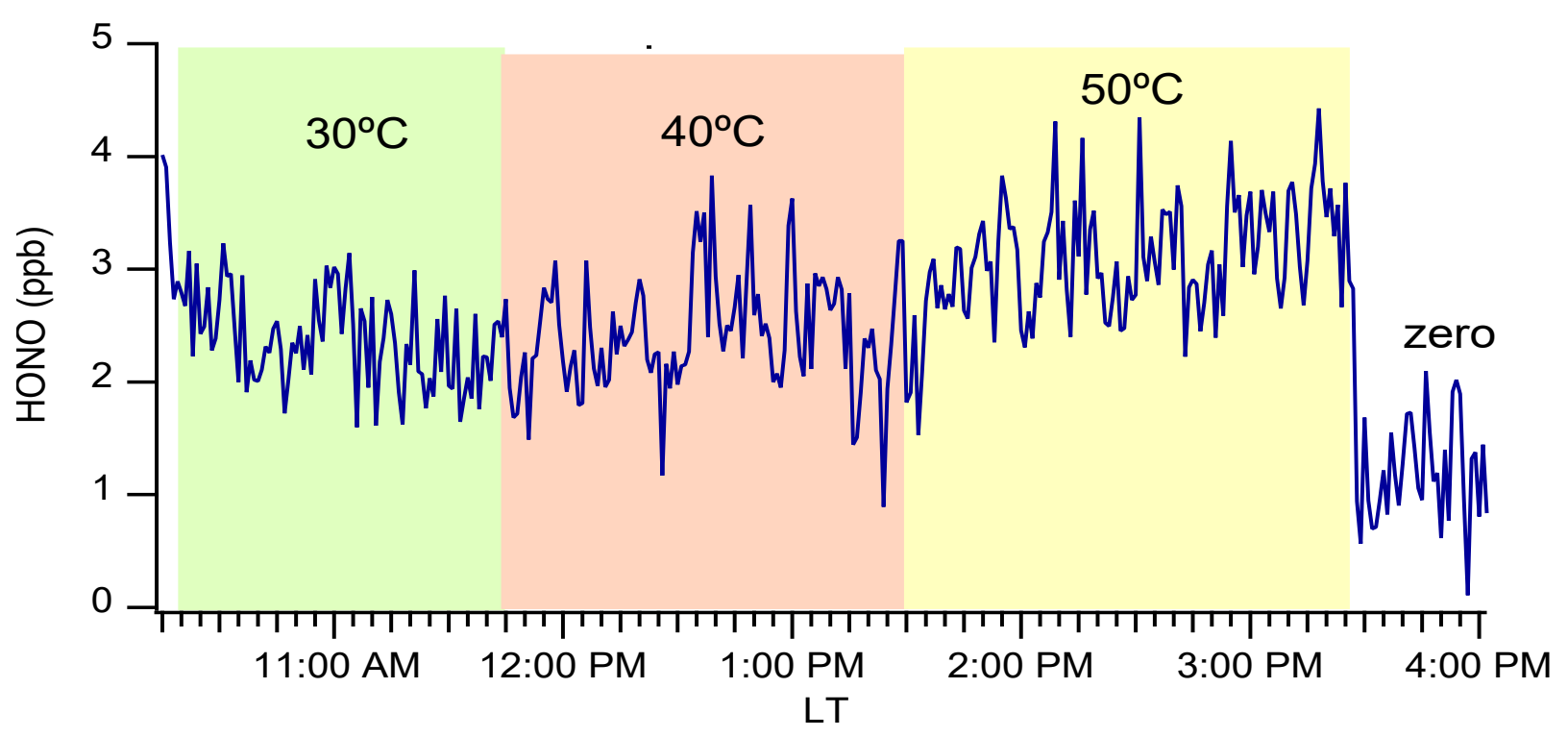

Figure S12. Time series of measured HONO output (ppb) for three different temperatures using HCl PD$6 b$.

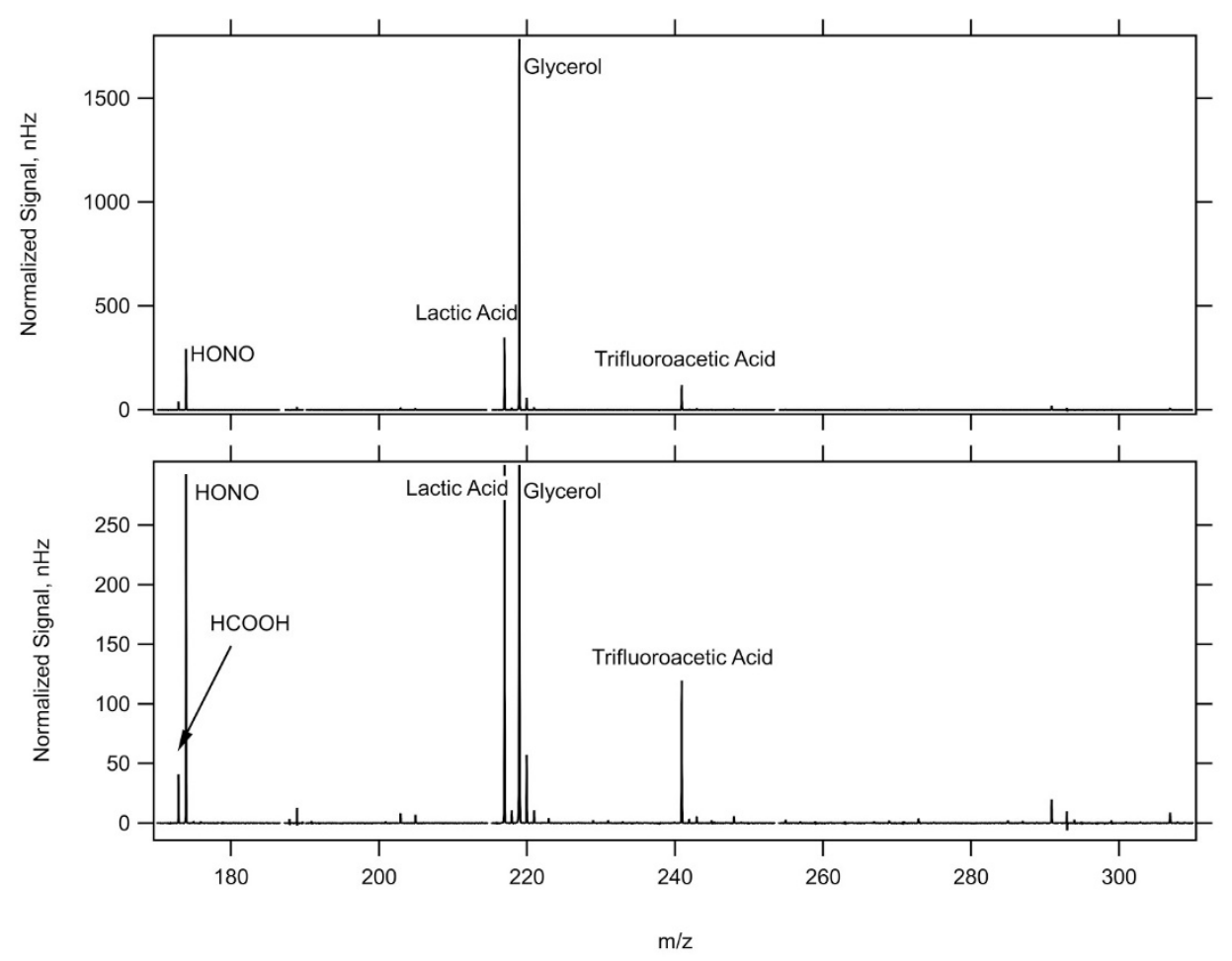

Figure S13. Ion scan of the HONO calibration source output made with the I-CIMS. Major ions observed in addition to HONO include glycerol from the coating solution, and lactic acid from skin contact with system components. Smaller quantities of formic and trifluoroacetic acids from the plastics used in the instrument assembly were also observed. 


\section{References}

Lucero, D. P.: Performance Characteristics of Permeation Tubes, Anal. Chem., 43(13), 1744-1749, doi:10.1021/ac60307a005, 1971.

Mitchell, G. D.: A review of permeation tubes and permeators, Sep. Purif. Methods, 29(1), 119-128, doi:10.1081/SPM-100100005, 2000.

Sander, R.: Compilation of Henry's law constants (version 4.0) for water as solvent, Atmos. Chem. Phys., 15(8), 4399-4981, doi:10.5194/acp-15-4399-2015, 2015.

Scaringelli, F. P., O'Keeffe, A. E., Rosenberg, E. and Bell, J. P.: Preparation of Known Concentrations of Gases and Vapors with Permeation Devices Calibrated Gravimetrically, Anal. Chem., 42(8), 871-876, doi:10.1021/ac60290a012, 1970. 